\section{Surprise rejection for Amgen's D-peptide}

The European Medicines Agency's (EMA) move to back approval for a new synthetic peptide drug with a D-amino acid backbone, which Amgen is developing for treating a common complication of kidney failure, makes its recent rejection by the US Food and Drug Administration (FDA) all the more mysterious. The EMA's Committee for Medicinal Human Products (CHMP) disclosed its positive recommendation for Parsabiv (etelcalcetide; AMG 416) in secondary hyperparathyroidism on September 16. The FDA issued a complete response letter to Amgen on August 24. The calcimimetic agent had hit the primary endpoint of two placebo-controlled Phase 3 trials in patients with secondary hyperparathyroidism, as well as a Phase 3 head-to-head study comparing it with the current standard of care, Amgen's soon-to-be generic blockbuster Sensipar (cinacalcet). In preclinical studies, Parsabivwhich comprises seven D-amino acids and one L-cysteine residue linked to a D-cysteinedemonstrated greater potency than an equivalent peptide based on L-amino acids. Its clinical profile also appeared promising. Ed Nemeth, an independent consultant based in Toronto, who is a co-discoverer of Sensipar, says, "When you look at the data that have been released, [they are] very good. I was surprised to hear it got a [complete response letter]," he says. Parsabiv was "a little more efficacious" and "a little less safe" than Sensipar, says Nemeth, previously CSO at NPS Pharmaceuticals (now part of Dublin-based Shire). It licensed Sensipar rights (excluding four Asian countries) to Thousand Oaks, California-based Amgen in 1996. Secondary hyperparathyroidism, a common complication of kidney failure, is characterized by increased secretion of parathyroid hormone in response to perturbations in mineral metabolism, including reduced serum levels of calcium. Etelcalcetide inhibits parathyroid hormone production by acting as an agonist of its negative regulator, 'calcium-sensing receptor', a G-protein-coupled receptor expressed by the cells of the parathyroid gland. Because it is dosed intravenously-Sensipar is an oral drug -it may lead to improved compliance, as patients would receive it at the conclusion of their dialysis sessions. In terms of safety, there was little to separate Parsabiv from Sensipar, apart from a fivefold increase in cardiac failure $(3.0 \%$ vs. $0.6 \%)$. "That would be the only thing," says Nemeth. But the events captured in that measure may not be highly significant from a clinical standpoint. "That could be simply be a change in left ventricular pressure."

Cormac Sheridan

\section{Seres's pioneering microbiome drug fails mid-stage trial}

On July 29, microbiome drug developer Seres Therapeutics announced interim results from an important phase 2 clinical trial of its lead compound SER-109, a stool-derived bacterial spore mixture for preventing recurrent Clostridium difficile infections. The study did not achieve its primary endpoint of reducing the relative risk of infection recurrence at up to eight weeks. Seres shares plummeted by roughly $70 \%$ that day, marking a loss of almost barely recovered since.

"These are unexpected clinical results," said CEO Roger Pomerantz in a press release. The infection recurrence rates in the SER109-treated groups failed to match expectations, prompting the company to review the results and the microbiome data it collected from patients and compare them with the results from the investigator-sponsored phase $1 \mathrm{~b}$ that had raised high hopes for the drug. The Cambridge, Massachusetts, company intends to consult with the US Food and Drug Administration and make any appropriate adjustments to its development plans. The company declined an interview for this story, "given that we are actively conducting a root cause investigation of the SER-109 phase 2 study," it said in an email.

Seres is the first company to conduct a well-controlled clinical study of a microbiome drug. The 24 -week phase 2 study enrolled 89 participants in the US and used a placebo control. C. difficile infection is the primary cause of antibiotic-associated colitis, and $15-20 \%$ of $\$ 1$ billion in the company's valuation, and have hospital-acquired antibiotic-associated diarrhea. Symptoms range from mild diarrhea to toxic megacolon, bowel perforation, septic shock and death.

In the phase 2 trial, at eight weeks, $C$. difficile infections had recurred in $44 \%$ of those receiving SER-109 compared with $53 \%$ of those who received placebo. When the data were stratified by age, $43 \%$ of participants under 65 years old treated with drug had a recurrence of infection versus $27 \%$ in the placebo group. In those 65 or older receiving the drug, the rate of recurrence was $45 \%$ versus $80 \%$ who got placebo.

"We will seek to fully understand why the phase 2 results are discordant from the prior phase $1 \mathrm{~b}$ data," Pomerantz told investors. In the phase $1 \mathrm{~b}$ study, $97 \%$ of the patients with recurrent $C$. difficile infections achieved a clinical cure. Those remarkable results were a major factor in Seres going public in July 2015 in an initial public offering that netted just under $\$ 140$ million (Nat. Biotechnol. 33, 787-788, 2015). Seres is now examining differences between the two studies to explain the "unexpected placebo and age-stratified recurrence data," Pomerantz said.

"It's a fascinating thing to try and figure out why the phase 2 didn't work," says trial investigator Elizabeth Hohmann, infectious disease specialist at Massachusetts General Hospital in Boston and also the senior author of the phase $1 \mathrm{~b}$ study (her laboratory produced the phase $1 \mathrm{~b}$ study material using the Seres process).

One possibility is that the patient population in phase 2 was too limited. "So many of

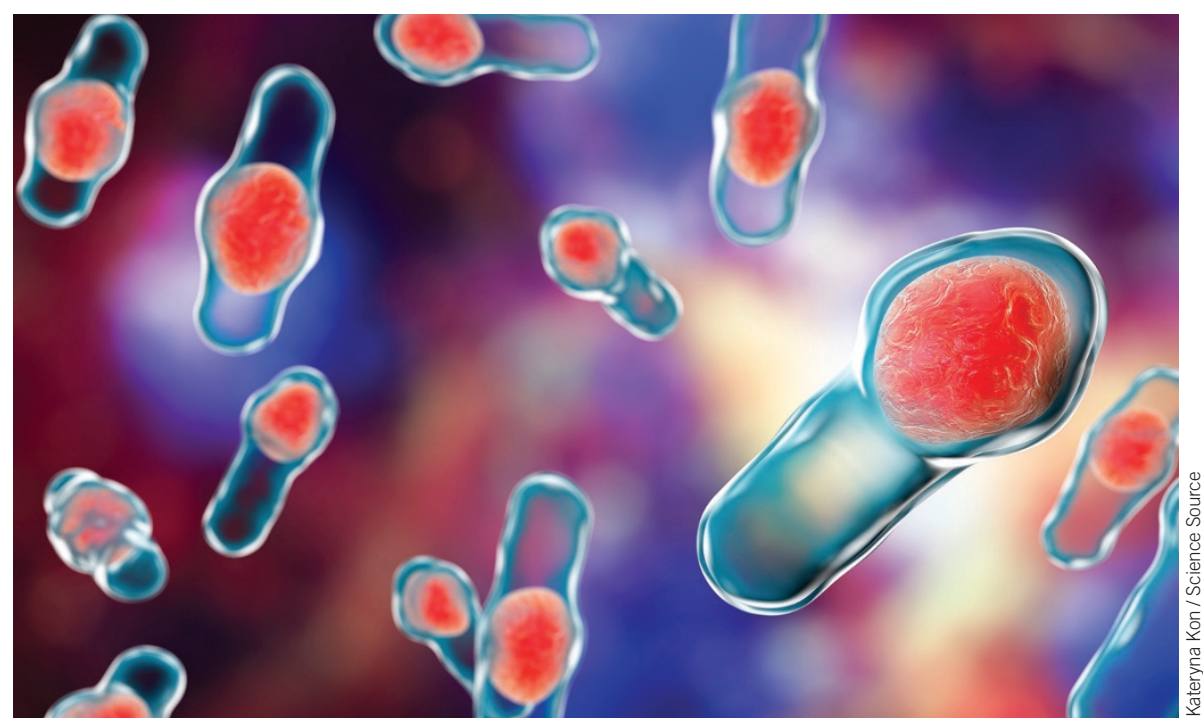

Clostridum difficile bacteria are normal inhabitants of the human intestine but can become pathogens when antibiotics disrupt the normal intestinal flora. 